\title{
Assessment of fat-mass loss during weight reduction in obese women.
}

Citation for published version (APA):

Fogelholm, M., van Marken Lichtenbelt, W. D., \& Westerterp, K. R. (1997). Assessment of fat-mass loss during weight reduction in obese women. Metabolism-Clinical and Experimental, 46(8), 968-975. https://doi.org/10.1016/S0026-0495(97)90089-5

Document status and date:

Published: 01/01/1997

DOI:

10.1016/S0026-0495(97)90089-5

Document Version:

Publisher's PDF, also known as Version of record

Document license:

Taverne

Please check the document version of this publication:

- A submitted manuscript is the version of the article upon submission and before peer-review. There can be important differences between the submitted version and the official published version of record.

People interested in the research are advised to contact the author for the final version of the publication, or visit the DOI to the publisher's website.

- The final author version and the galley proof are versions of the publication after peer review.

- The final published version features the final layout of the paper including the volume, issue and page numbers.

Link to publication

\footnotetext{
General rights rights.

- You may freely distribute the URL identifying the publication in the public portal. please follow below link for the End User Agreement:

www.umlib.nl/taverne-license

Take down policy

If you believe that this document breaches copyright please contact us at:

repository@maastrichtuniversity.nl

providing details and we will investigate your claim.
}

Copyright and moral rights for the publications made accessible in the public portal are retained by the authors and/or other copyright owners and it is a condition of accessing publications that users recognise and abide by the legal requirements associated with these

- Users may download and print one copy of any publication from the public portal for the purpose of private study or research.

- You may not further distribute the material or use it for any profit-making activity or commercial gain

If the publication is distributed under the terms of Article $25 \mathrm{fa}$ of the Dutch Copyright Act, indicated by the "Taverne" license above, 


\title{
Assessment of Fat-Mass Loss During Weight Reduction in Obese Women
}

\author{
G. Mikael Fogelholm, Harri T. Sievänen, Wouter D. van Marken Lichtenbelt, and Klaas R. Westerterp
}

\begin{abstract}
Methods for assessing body fat mass (FM) loss were compared in 32 obese (body mass index [BMI], 29 to $41 \mathrm{~kg} / \mathrm{m}^{2}$ ] premenopausal women before and after a weight loss of $13.0 \pm 3.4 \mathrm{~kg}$ (mean \pm SD). A four-component (4C) model was used as the criterion. The other methods were as follows: three-component models (body density with total body water [3W] or bone minerals [3M]), underwater weighing, dual-energy x-ray absorptiometry ([DXA] XR-26, software 2.5.2; Norland, Ft Atkinson, WI), bioelectric impedance analysis (B|A) with an obese-specific equation (Segal et al), skinfolds (Durnin and Womersley), and an equation with BMI (Deurenberg et al). The $3 \mathrm{~W}$ model (bias $\pm \mathrm{SD}, 0.5 \pm 0.4 \mathrm{~kg}), \mathrm{XR}-26(0.6 \pm 2.1 \mathrm{~kg})$, and BMI equation $(-0.3 \pm 2.1 \mathrm{~kg})$ gave practically unbiased mean estimations of fat loss. All other methods underestimated fat loss by at least $1.6 \mathrm{~kg}$ (range of bias, -2.7 to $-1.6 \mathrm{~kg}$ ). The small bias $(0.7 \pm 1.0 \mathrm{~kg}$ ) between underwater weighing and model $4 \mathrm{C}$ before weight reduction indicates that the two-component assumptions were valid in premenopausal, weight-stable obese women. However, particularly the water fraction of the fat-free body component (4C model) was increased after weight reduction (before, $72.9 \% \pm 1.4 \%$; after, $75.7 \% \pm 2.2 \%$ ), making both underwater weighing and the $3 \mathrm{M}$ model uncertain for assessment of body composition changes. A general tendency for overestimating FM was seen before and more clearly after weight reduction. However, most methods underestimated fat loss, apparently because of unexpected changes in hydration of the fat-free body component.
\end{abstract}

Copyright $\odot 1997$ by W.B. Saunders Company

$\mathbf{T}$ HE MOLECULAR COMPOSITION of the body in vivo is assessed with many different methods that vary in complexity and cost. All methods are principally indirect, because an unknown body component is quantified by a mathematical function from a measured property, from a known body component, or from both. ${ }^{1}$ Examples of properties measured in body component analyses are body density (underwater weighing), $x$-ray attenuation (dual-energy $x$-ray absorptiometry [DXA]), dilution of deuterium in body fluids (total body water [TBW] assessment), body electrical resistance (bioelectric impedance analysis, or bioimpedance [BIA]), and skinfold thickness. ${ }^{1,2}$

Many of these methods (underwater weighing, deuterium dilution, BIA, and skinfolds) rely on the two-component model assumptions, that is, on a known and constant composition of the fat-free body component. ${ }^{2}$ However, these assumptions, and consequently the mathematical functions relating the measured properties to an unknown component, might be less valid in specific populations such as obese people. Problems with the composition of the fat-free body component may be at least partly overcome by three- or four-component (multicomponent) models in which body density is combined with body mineral content (3M model), TBW ( $3 \mathrm{~W}$ model), or both (4C model). 3

When studying the effects on different treatments of obesity, valid data on body composition changes are fundamental. Nevertheless, few studies have compared the composition of weight loss by different methods in obese people. ${ }^{4-9}$ Only Albu et $\mathrm{al}^{4}$ used multicomponent models in their study. The choice of criterion method is important, because changes in $\mathrm{TBW}^{4,10}$ and

From the Urho Kaleva Kekkonen Institute for Health Promotion Research, Tampere, Finland; and the Department of Human Biology, University of Limburg, Maastricht, The Netherlands.

Submitted November 21, 1996; accepted February 17, 1997.

Supported by the Ministry of Education, Finland, the Yrjö Jahnsson Foundation, Nycomed Pharma, Leiras Oy.

Address reprint requests to G. Mikael Fogelholm, DSc, The UKK Institute, P.O.B. 30, FIN-33501 Tampere, Finland.

Copyright $\odot 1997$ by W.B. Saunders Company

0026-0495/97/4608-0021\$03.00/0 bone minerals $s^{4,11,12}$ during weight reduction affect the traditional two-component model assumptions. ${ }^{2}$

In the present study, we assessed body fat mass (FM) in obese premenopausal women before and after a 12-week weightreduction program. The $4 \mathrm{C}$ model was used as the criterion method, and the other methods (three-component models, underwater weighing, DXA, BIA, skinfolds, and equation with BMI) were related to the criterion. The results contribute to the present understanding on the assessment of FM and fat-free mass (FFM) changes in obese subjects.

\section{SUBJECTS AND METHODS}

\section{Participants and General Study Design}

Thirty-two obese (body mass index [BMI], 29 to $41 \mathrm{~kg} / \mathrm{m}^{2}$ ) but otherwise healthy premenopausal (aged 30 to 45 years) women volunteered for this study, which was approved by the Ethics Committee of the UKK Institute for Health Promotion Research, Tampere, Finland. Written informed consent was obtained from all the volunteers. All subjects had been weight-stable $( \pm 3 \mathrm{~kg})$ for at least 3 months before the study. The subjects were not taking any medication or oral contraceptives. Three subjects used an estrogen-releasing coil. None of the subjects were physically active, smoking, pregnant, or lactating.

The subjects participated in a 12 -week weight-reduction program at the UKK Institute. The program consisted of three phases: week 1, low-energy diet based on a meal-exchange system; weeks 2 to 9 , very-low-energy diet (Nutrilett; Nycomed Pharma, Oslo, Norway); and weeks 10 to 12 , low-energy diet. The estimated mean \pm SD energy and protein intakes calculated from food records by Micronutrica software (The Social Insurance Institution, Turku, Finland) were as follows: week $1,4.2 \pm 0.9 \mathrm{MJ} / \mathrm{d}$ and $62 \pm 15 \mathrm{~g} / \mathrm{d}(1 \times 4$-day record $)$; weeks 2 to $9,2.7 \pm 0.3 \mathrm{MJ} / \mathrm{d}$ and $71 \pm 7 \mathrm{~g} / \mathrm{d}(3 \times 4$-day record); and weeks 10 to $12,4.6 \pm 1.2 \mathrm{MJ} / \mathrm{d}$ and $61 \pm 19 \mathrm{~g} / \mathrm{d}(1 \times 4$-day record $)$.

The subjects met weekly in small groups. All meetings were overseen by a nutritionist. The meeting topics included instructions for lowenergy and very-low-energy diets, general knowledge on diet and weight maintenance, and relapse-prevention techniques. All subjects were also weighed before every meeting.

The "pre" body composition measurements were made 3 to 7 days before the start of the weight-reduction program. The "post" measurements were made 4 to 7 days after completion of the weight-reduction program. Excluding an overnight fast immediately beforehand, normal eating was allowed during the days preceding the measurements. All 
body composition measurements were made within a period of 5 hours in the following sequence: body weight, BIA, DXA, skinfolds, and underwater weighing. The subjects came to the laboratory after a 12-hour fast, but they were given a light breakfast (a glass of juice and a small sandwich) after BIA measurements.

\section{Measurements of Body Properties}

Body weight was measured with the subjects in underwear, after an overnight fast, on a high-precision scale (F150S-D2; Sartorius, Goettingen, Germany). Body density was measured by underwater weighing after full exhalation (presumably at residual lung volume) as described recently. ${ }^{13}$ Residual lung volume was measured two to four times before underwater weighing, using the helium-dilution method.

Total body bone mineral content $\left(\mathrm{BMC}_{\mathrm{T}}\right)$ and $\mathrm{FM}$ were determined with a DXA scanner (XR-26; Norland, Fort Atkinson, WI) as described previously. ${ }^{13}$ Subject positioning and scanning were performed according to the manufacturer's recommendations. $\mathrm{BMC}_{\mathrm{T}}$ and $\mathrm{FM}$ were calculated from the scan data by new Norland total body composition scan software (version 2.5.2). According to repeated measurements of 18 subjects, the precision in vivo for $\mathrm{BMC}_{\mathrm{T}}$ and $\mathrm{FM}$ measurements was $1.5 \%$ and $1.2 \%$, respectively (unpublished observations, fall and winter 1994-95). The scanner was calibrated daily, and its performance was controlled with our quality-assurance program. ${ }^{14}$

TBW was assessed by deuterium dilution. The subjects received an orally administered dose of ${ }^{2} \mathrm{H}_{2} \mathrm{O}(0.1 \mathrm{~g} / \mathrm{L}$ estimated TBW $)$. The appropriate amount of ${ }^{2} \mathrm{H}_{2} \mathrm{O}(99.8 \%$; Akademie der Wissenschaften, Leipzig, Germany) was weighed and diluted with tap water to $0.075 \mathrm{~L}$ for intake. Isotope enrichment in the body fluid was measured in urine. The ${ }^{2} \mathrm{H}_{2} \mathrm{O}$ dose was given to the subjects on the evening before the measurements. Before administration of the dose, background urine samples were taken. The other urine samples were taken in the morning, 10 hours after the dose, from the second voiding (first voiding at 5 to 7 $\mathrm{AM})$. Isotope abundance in urine was determined in duplicate with an isotope-ratio mass spectrometer (Aqua Sira; Isogas, Middlewich, Cheshire). TBW was calculated as the ${ }^{2} \mathrm{H}$ dilution space divided by 1.04 , correcting for the exchange of ${ }^{2} \mathrm{H}$ label with nonaqueous $\mathrm{H}$ of body solids. ${ }^{15}$

Body resistance was measured after an overnight fast and within 30 minutes of the last voiding by a standard whole-body right-sided tetrapolar bioimpedance analyzer (BIA-106 analyzer; RJL Systems Inc, Detroit, MI) with subjects in a supine position after a 15 -minute resting period. The procedure was as described by Lukaski et al. ${ }^{16}$

Using a Harpenden caliper (Harpenden, Pembrokeshire, UK), four skinfolds measurements were taken from the following sites ${ }^{17}$ : triceps (posterior aspect of the arm at the midpoint between the lateral projection of the acromial process and the inferior border of the olecranon process of the ulna), biceps (anterior aspect of the arm at the same level as the triceps skinfold), subscapula (inferior to the inferior angle of the scapula at a $45^{\circ}$ angle), and suprailiac (horizontal skinfold at the midaxillary line immediately superior to the iliac crest). The nondominant side of the body was used for all measurements. Three readings (to the nearest $0.1 \mathrm{~mm}$ ) from each site were obtained, and the mean value was used in calculations.

\section{Calculation of Body Composition}

In addition to the data obtained using DXA (XR-26) software 2.5.2., body composition was calculated from seven different equations:

1. $4 \mathrm{C}$ model, used as the first criterion method, with an equation presented by Lohman': $\mathrm{BF} \%=\left(2.747 / \mathrm{D}_{\mathrm{b}}-0.714 \times \mathrm{TBW} /\right.$ $\left.\mathrm{WT}+1.146 \times \mathrm{BMC}_{\mathrm{T}} / \mathrm{WT}-2.0503\right) \times 100$, where $\mathrm{BF} \%$ is body fat as a percent of body weight, $\mathrm{D}_{\mathrm{b}}$ is body density in grams per cubed centimeter from underwater weighing, TBW is obtained by deuterium dilution, $\mathrm{BMC}_{\mathbf{T}}$ is obtained by DXA, and WT is body weight in kilograms.
2. $3 \mathrm{~W}$ using the $\operatorname{Siri}^{18}$ equation: $\mathrm{BF} \%=\left(2.118 / \mathrm{D}_{\mathrm{b}}-0.78 \times \mathrm{TBW} /\right.$ WT -1.354$) \times 100$.

3. $3 \mathrm{M}$ using the Lohman $^{19}$ equation: $\mathbf{B F \%}=(6.386 /$ $\left.\mathrm{D}_{\mathrm{b}}+\left[3.961 \times \mathrm{BMC}_{\mathrm{T}}\right] /[0.824 \times \mathrm{WT}]-6.090\right) \times 100$.

4. Underwater weighing (two-component model) with the Siri ${ }^{18}$ equation: $\mathrm{BF} \%=\left(4.95 / \mathrm{D}_{b}-4.50\right) \times 100$.

5. BIA with equation from Segal et $\mathrm{a}^{20}$ for obese subjects: $\mathrm{FFM}=$ $9.3794+0.0009 \times \mathrm{HT}^{2}-0.015 \times \mathrm{R}+0.3 \times \mathrm{WT}-0.07 \times$ age, where FFM is in kilograms, HT is height in centimeters, and R is resistance in ohms.

6. Skinfolds with the Durnin and Womersley ${ }^{21}$ equation: $D_{b}=1.133$ $-0.0612 \times(\log \Sigma S)$, where $\Sigma S$ is the sum of triceps, biceps, subscapular, and suprailiac skinfold thicknesses. Because of difficulties in measuring the subscapular skinfold, the following equation was used for three subjects ${ }^{21}: D_{b}=1.1267-0.0626 \times$ $(\log \Sigma S)$, where $\Sigma S$ is the sum of triceps, biceps, and suprailiac skinfold thicknesses. BF\% was calculated with the Siri ${ }^{18}$ equation.

7. Equation with BMI by Deurenberg et $\mathrm{al}^{22}: \mathrm{BF} \%=1.2 \times \mathrm{BMI}+$ $0.23 \times$ age -5.4 .

Using BF\% from equations 1 to 4,6 , and 7, $\mathrm{FM}=(\mathrm{BF} \% / 100) \times \mathrm{WT}$, and $\mathrm{FFM}=\mathrm{WT}-\mathrm{FM}$. Using FFM from equation 5, FM $=\mathrm{WT}-$ FFM.

\section{Statistical Analyses}

Methods comparisons were made as recommended by Altman and Bland. ${ }^{23}$ The difference (bias) between the criterion and an alternative method was calculated by subtracting the $4 \mathrm{C}$ result from the alternative result. Hence, a positive bias indicates a relative overestimation of FM by the alternative method. The difference was considered significant when the $95 \%$ confidence interval of the mean difference did not include the zero value. Statistical associations between the magnitude of measurement (mean of criterion and alternative results) and bias (alternative minus criterion) were calculated by Pearson productmoment correlations. BMDP Statistical Software (University of California, Berkeley, CA, 1990 version) was used for all statistical analyses.

\section{RESULTS}

The mean weight loss was $13.0 \mathrm{~kg}$, with a range of 7.0 to 20.8 (Table 1). BMC and, unexpectedly, TBW were practically unchanged. The change in TBW had a weak nonsignificant relation with the change in weight $(r=.30, P=.1)$. The correlation between changes in $\mathrm{BMC}_{\mathrm{T}}$ and weight was even weaker $(r=.19, P=.29)$.

The subjects' body composition before and after weight

Table 1. Properties and Body Components (mean \pm SD) in Obese Women ( $N=32$ ) Before and After a 12-Week Weight-Reduction Program

\begin{tabular}{lccc}
\hline \multicolumn{1}{c}{ Property/Component } & Before & After & Change $^{*}$ \\
\hline Weight $(\mathrm{kg})$ & $93.7 \pm 10.6$ & $80.7 \pm 10.4$ & $-13.0 \pm 3.4$ \\
BMI $\left(\mathrm{kg} / \mathrm{m}^{2}\right)$ & $34.7 \pm 3.9$ & $29.9 \pm 3.8$ & $-4.8 \pm 1.3$ \\
Body density $\left(\mathrm{g} / \mathrm{cm}^{3}\right)$ & $1.002 \pm 0.010$ & $1.011 \pm 0.012$ & $+0.010 \pm 0.007$ \\
Residual lung & & & \\
$\quad$ yolume (L) & $1.38 \pm 0.23$ & $1.01 \pm 0.01$ & $-0.37 \pm 0.26$ \\
Bone mineral & & & \\
$\quad$ content (g) & $2,968 \pm 282$ & $2,994 \pm 252$ & $+27 \pm 181$ \\
Resistance (ohms) & $490 \pm 40$ & $506 \pm 37$ & $+16 \pm 21$ \\
TBW (L) & $38.3 \pm 2.8$ & $38.2 \pm 3.4$ & $-0.1 \pm 1.3$ \\
Skinfolds (mm) $\dagger$ & $132 \pm 18$ & $93 \pm 23$ & $-38 \pm 14$ \\
\hline
\end{tabular}

*All changes, excluding bone mineral content and TBW, were significantly different from zero $(P<.05)$.

tSum of biceps, triceps, subscapular, and suprailiac skinfolds. 
reduction by different methods is presented in Table 2 . Judged from the $4 \mathrm{C}$ model results, FM was reduced by $-10.9 \pm 2.9 \mathrm{~kg}$, which implies that $85 \% \pm 17 \%$ of the weight loss was fat. The proportion of fat loss in total weight loss by the alternative methods was as follows: $3 \mathrm{~W}, 88 \% \pm 16 \% ; 3 \mathrm{~B}, 64 \% \pm 31 \%$; underwater weighing, $72 \% \pm 23 \%$; DXA, $89 \% \pm 15 \%$; BIA, $65 \% \pm 4 \%$; skinfolds, $72 \% \pm 10 \%$; and BMI equation, $81 \% \pm$ $9 \%$.

Agreement was good between the $4 \mathrm{C}$ and $3 \mathrm{~W}$ models in the assessment of FM changes $(0.5 \pm 0.4 \mathrm{~kg})$, although it was different $(P<0.05)$ from zero. The $95 \%$ limits of agreement were -0.4 to $+1.3 \mathrm{~kg}$ (Fig 1a). Both the $3 \mathrm{M}$ model and underwater weighing underestimated $(P<.05)$ FM reduction (Fig $1 \mathrm{~b}$ and $\mathrm{c}$ ), with SDs of 2.4 and $1.6 \mathrm{~kg}$ for the $3 \mathrm{M}$ model and underwater weighing, respectively. The individual errors versus the $4 \mathrm{C}$ model were substantially greater $(-8.4$ to +2.0 for $3 \mathrm{M}$ and -4.9 to 1.3 for underwater weighing) than the corresponding differences for $3 \mathrm{~W}$ versus $4 \mathrm{C}$. The relative bias of the $3 \mathrm{M}$ model showed a moderate positive association (bias $=-5.4+$ $0.29 \times$ mean, $R^{2}=.14, P=.03$ ) with an increasing magnitude of fat loss (mean of $4 \mathrm{C}$ and $3 \mathrm{M}$ models). This implies that underestimation by the $3 \mathrm{M}$ model tended to be greater in subjects who lost the least amount of body fat.

BIA and skinfold thicknesses underestimated $(P<.05)$ fat loss (Fig 2a to d). In contrast, DXA (XR-26) and the equation including only weight divided by height squared (BMI) yielded an unbiased mean estimation of FM loss. The SDs for bias versus the $4 \mathrm{C}$ model were $2.1 \mathrm{~kg}$ (DXA), $1.6 \mathrm{~kg}$ (BIA), $1.9 \mathrm{~kg}$ (skinfolds), and $2.1 \mathrm{~kg}$ (BMI). The relative underestimation of FM loss by BIA and skinfolds tended to be greater with increasing size of the measurement (BIA: bias $=-0.3-0.22 \times$ mean, $R^{2}=.12, P=.05$; skinfolds: bias $=0.9-0.25 \times$ mean, $R^{2}=.10, P=.07$ ).

Agreement between the $4 \mathrm{C}$ and $3 \mathrm{~W}$ models was good both before and after weight reduction, because individual differences were, at most, $1 \mathrm{~kg}$ absolute FM (Table 3 ). The mean biases were small, although the bias before weight reduction was statistically different $(P<.05)$ from zero. When the $4 \mathrm{C}$ model was used as the criterion, DXA and the equation including BMI significantly overestimated FM both before and after weight reduction. The $3 \mathrm{M}$ model, underwater weighing, and BIA overestimated FM only after weight reduction. The bias between skinfolds and the $4 \mathrm{C}$ model was not significant on either measurement point.

The bias for DXA became more positive with increasing size of the measurement (before: bias $=-1.5+0.13 \times$ mean, $R^{2}=.26, \quad P=.003 ; \quad$ after: bias $=0.33+0.09 \times$ mean, $R^{2}=.18, P=.01$ ). In contrast, the bias for BIA (before: bias $=8.4-0.18 \times$ mean $, \quad R^{2}=.29, \quad P=.001$; after: bias $=9.1-0.18 \times$ mean, $\left.R^{2}=.25, P=.004\right)$ and skinfolds (before: bias $=13.3-0.35 \times$ mean, $R^{2}=.52, P<.001$; after: bias $=9.1-0.27 \times$ mean, $\left.R^{2}=.45, P<.001\right)$ became more negative (Table 2). However, because the deviation (spread) of the difference was not related to the size of the measurement, the use of logarithmic plots was not indicated. ${ }^{23}$

\section{DISCUSSION}

\section{Multicomponent Models and Underwater Weighing}

The mathematical function relating body density directly to body fatness (two-component model) is based on a constant density of both FM and FFM. However, the assumed density of FFM $\left(1.100 \mathrm{~g} / \mathrm{cm}^{3}\right.$ in the equation of $\left.\mathrm{Sir}^{18}\right)$ is dependent on the relative masses of water and minerals. ${ }^{2}$ For instance, when the density of FFM is less than $1.100 \mathrm{~g} / \mathrm{cm}^{3}$ (for instance, because of relatively higher TBW or lower $\mathrm{BMC}_{\mathrm{T}}$ ), the equation by $\mathrm{Siri}^{18}$ overestimates FM. The density of FFM in obese people is uncertain $^{24-27}$ and is perhaps affected by weight reduction. ${ }^{28}$

We used the $4 \mathrm{C}$ model by Lohman. ${ }^{19}$ All multicomponent models are obviously affected by the method used for assessing TBW (deuterium, tritium, or ${ }^{18} \mathrm{O}$ dilution, and choice of equilibration time) and bone minerals (DXA or DPA, manufacturer, software version, etc.). In addition, the technique for hydrostatic weighing is difficult to standardize between laboratories. Therefore, it should be realized that our $4 \mathrm{C}$ results are not necessarily comparable to results obtained in another laboratory.

Comparisons of the $4 \mathrm{C}$ model against three- and twocomponent models give an indication of how removing one or more properties from the mathematical function affects the outcome. However, these comparisons are not independent, because all mathematical functions include one or two common properties. Compared against the $4 \mathrm{C}$ model, the relative validity of the $3 \mathrm{~W}$ model as a method for assessment of FM changes during weight reduction was good both on a group (bias) and

Table 2. Body Composition (mean \pm SD) Assessed by Different Methods in 32 Obese Premenopausal Women Before and After Weight Reduction

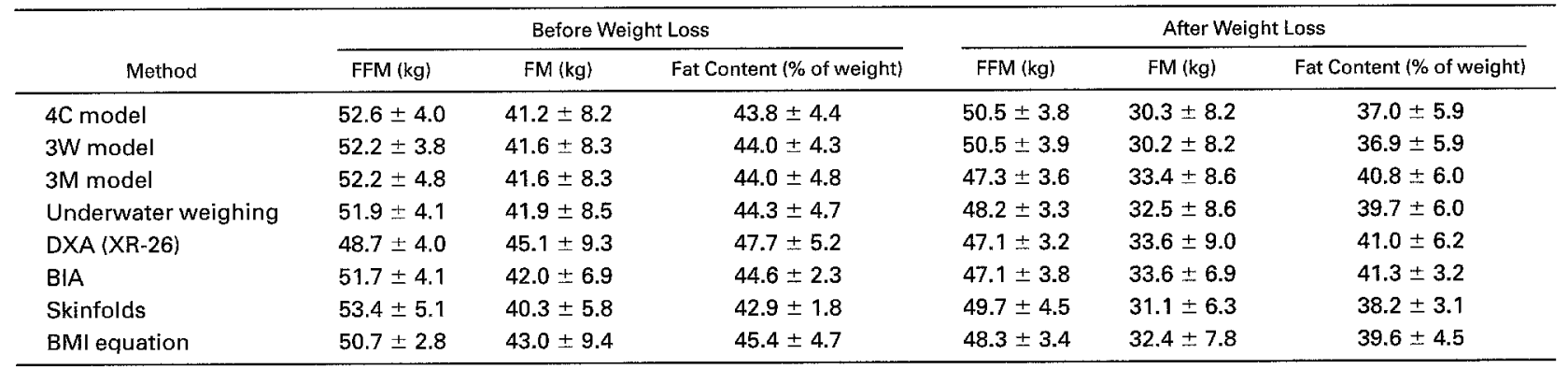

*Equations by Segal et al. ${ }^{20}$

tEquations by Durnin and Womersley. ${ }^{21}$

\#Equation by Deurenberg et al. ${ }^{22}$ 

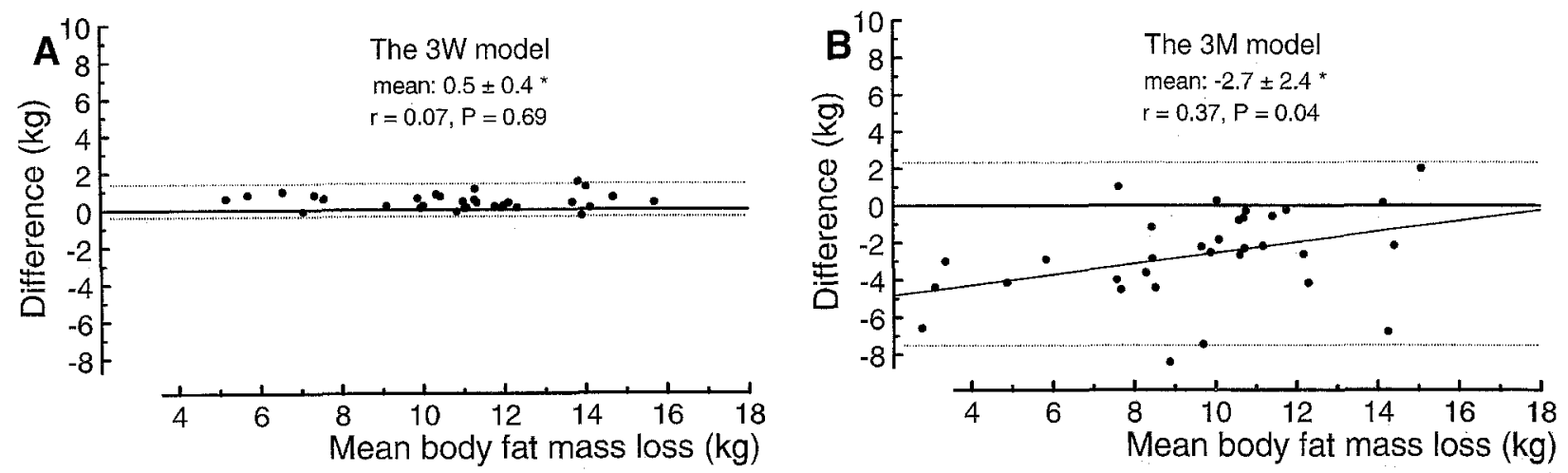

Fig 1. (a to c) Comparison between the $4 \mathrm{C}$ model and other models including body density in assessment of fat loss during weight reduction in 32 obese women: association between the mean of 2 methods and the difference of $4 \mathrm{C}$ model minus the alternatives. (....) $95 \%$ limits of agreement; *bias significantly $(P<.05)$ different from zero.
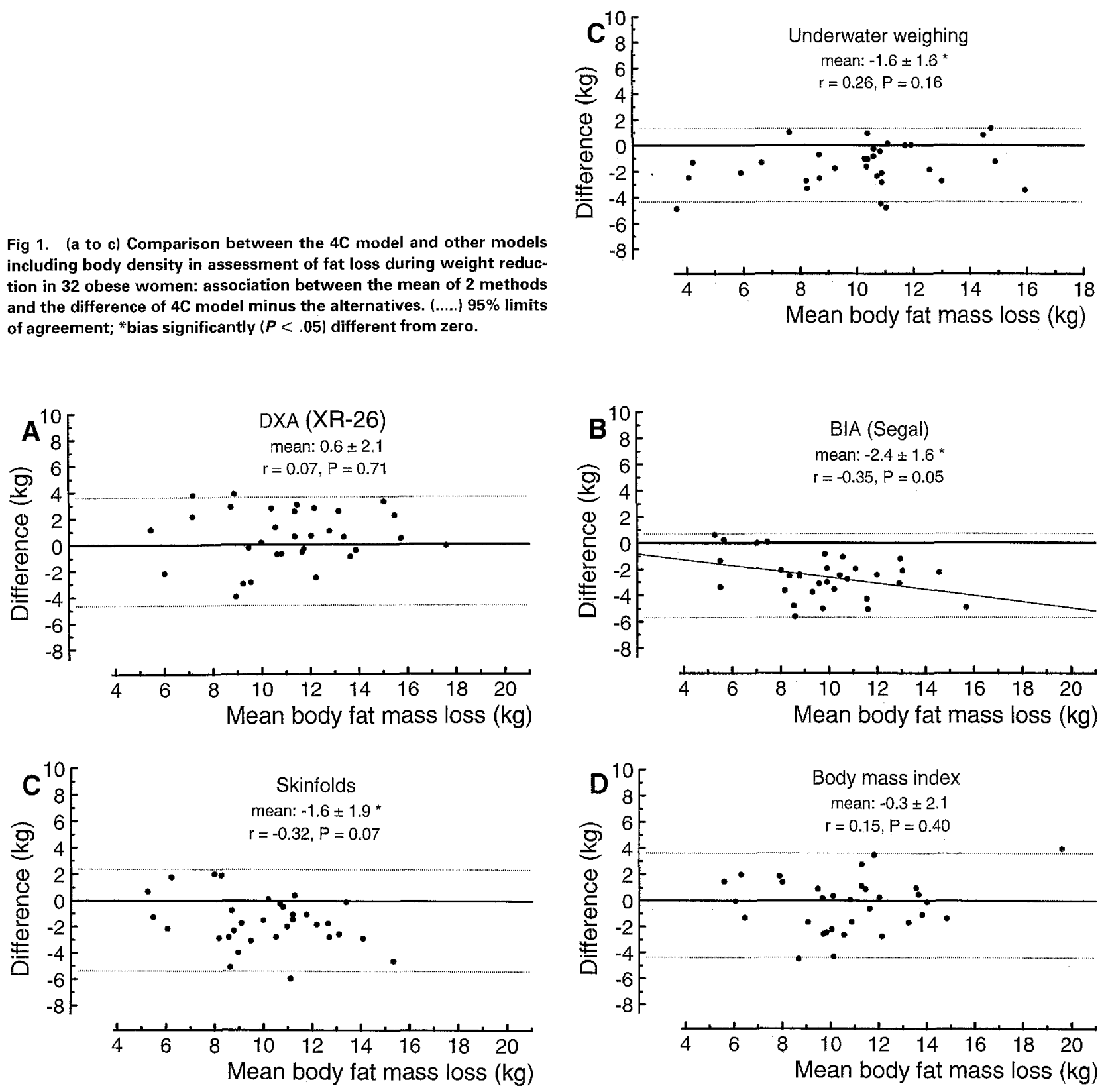

Fig 2. (a to d) Comparison between the $4 \mathrm{C}$ model against DXA, BIA, skinfolds, and BMI equation in assessment of fat loss during weight reduction in 32 obese women: association between the mean of 2 methods and the difference of $4 \mathrm{C}$ model minus the alternatives. (....) $95 \%$ limits of agreement; * bias significantly $(P<.05)$ different from zero. 
Table 3. Comparison of FM (kg) Assessment by the 4C Model Against Alternatives in 32 Obese Women Before and After a 12-Week Weight-Reduction Program

\begin{tabular}{|c|c|c|c|c|c|c|}
\hline \multirow[b]{2}{*}{ Method } & \multicolumn{3}{|c|}{ Before Wẹight Loss } & \multicolumn{3}{|c|}{ After Weight Loss } \\
\hline & Mean Error \pm SDt & $95 \%$ LOA & Associations & Mean Error \pm SD $\dagger$ & $95 \%$ LOA & Associationsł \\
\hline $3 \mathrm{~W}$ model & $0.4 \pm 0.3^{*}$ & $-0.2-1.0$ & & $0.0 \pm 0.3$ & $-0.7-0.6$ & \\
\hline Underwater weighing & $0.7 \pm 1.0$ & $-1.4-2.7$ & & $2.3 \pm 1.6^{*}$ & $-1.0-5.5$ & \\
\hline DXA (X) & $3.9 \pm 2.2^{*}$ & $-0.5-8.4$ & .51 & $3.3 \pm 1.9 *$ & $-0.6-7.2$ & .43 \\
\hline BIA§ & $0.9 \pm 2.5$ & $-4.2-6.0$ & -.54 & $3.3 \pm 2.7^{*}$ & $-2.2-8.8$ & -.50 \\
\hline BMI equation & $1.9 \pm 3.4^{*}$ & $-5.1-8.8$ & & $2.1 \pm 3.3^{*}$ & $-4.6-8.8$ & \\
\hline
\end{tabular}

* Significantly $(P<.05)$ different from zero.

†Error $=\mathrm{FM}(\mathrm{kg})$ by the alternative $-\mathrm{FM}$ by the $4 \mathrm{C}$ model.

$\neq$ Significant $(P<.003$ ) associations (Pearson correlation coefficients) between the bias and the size of the measurement.

$\$$ Equations by Segal et al.20

Equations by Durnin and Womersley. ${ }^{21}$

qEquation by Deurenberg et al.22

individual (error) level. In contrast, the $3 \mathrm{M}$ model and underwater weighing (a two-component model) significantly underestimated fat loss with a much larger individual inaccuracy. These comparisons suggest that the variation in $\mathrm{TBW}$, which is not included in $3 \mathrm{M}$ or underwater weighing calculations, affects estimations of fat loss during marked weight reduction.

The water fraction of $\mathrm{FFM}_{4 \mathrm{c}}$, calculated as $100 \times(\mathrm{TBW} /$ FFM), was $72.9 \% \pm 1.4 \%$ (range, $70.0 \%$ to $75.5 \%$ ) before and $75.7 \% \pm 2.2$ (range, $72.5 \%$ to $80.6 \%$ ) after weight reduction. The degree of hydration was close to the traditional twocomponent model assumptions ( $72 \%$ to $73 \%$ of FFM $)^{2,18}$ before weight reduction, but clearly increased after weight reduction.

We calculated a theoretical density for FFM by two methods. In the two-component approach, ${ }^{18} 1 / \mathrm{D}_{\mathrm{b}}=(\mathrm{FM} / \mathrm{WT}) / \mathrm{D}_{\mathrm{fm}}+$ (FFM/WT)/ $\dot{\mathrm{D}}_{\text {ffm }}$, where D is density of the total body (b) and WT is body weight. (Throughout, ffm and $\mathrm{fm}$ are FFM and FM.) If $D_{\text {fm }}$ is assumed to be $0.9 \mathrm{~g} / \mathrm{cm}^{3},{ }^{18}$ then $D_{\text {ffm }}=(F F M / W T) /(1 /$ $\left.\mathrm{D}_{\mathrm{b}}-[\mathrm{FM} / \mathrm{WT}] / 0.9\right)$. Replacing $\mathrm{D}_{\mathrm{b}}, \mathrm{FM}, \mathrm{FFM}$, and WT by the results calculated from underwater weighing $\left(D_{b}\right)$ and the $4 \mathrm{C}$ model (FM and FFM), $D_{\text {ffm }}$ was $1.097 \pm 0.005$ and $1.090 \pm$ $0.007 \mathrm{~g} / \mathrm{cm}^{3}$ before and after weight reduction, respectively. Using the $4 \mathrm{C}$ equation presented by Fuller et al, ${ }^{29}$ in which $\mathrm{D}_{\mathrm{ffm}}=\left(0.710 \mathrm{TBW}+3.050 \mathrm{WT}-2.747 \mathrm{WT} / \mathrm{D}_{\mathrm{b}}-1.460 \mathrm{BMC}_{\mathrm{T}}\right) /$ $\left(0.788 \mathrm{TBW}+2.276 \mathrm{WT}-2.050 \mathrm{WT} / \mathrm{D}_{\mathrm{b}}-1.621 \mathrm{BMC}_{\mathrm{T}}\right)$, the estimated $D_{\text {frm }}$ was $1.102 \pm 0.005$ (before) and $1.095 \pm 0.007$ (after) $\mathrm{g} / \mathrm{cm}^{3}$.

These calculations indicate that the uncertain assumption for the two-component model $\left(D_{\text {ffm }}=1.100 \mathrm{~g} / \mathrm{cm}^{3}\right)$ was valid in weight-stable, premenopausal women, thus agreeing with the conclusions of Fuller et al. ${ }^{27}$ However, using either mathematical approach, the estimated $D_{\text {ffm }}$ was $0.007 \mathrm{~g} / \mathrm{cm}^{3}$ lower after weight reduction, as a result of increased hydration of FFM. Consequently, both the $3 \mathrm{M}$ model and underwater weighing (constant water fraction of FFM assumed) overestimated FM after weight reduction and underestimated FM loss.

When assessing body composition during weight reduction, the timing of measurements might be critical regarding the assumptions for FFM density. Because we anticipated that dietary restriction could be associated with water loss, ${ }^{28}$ the subjects were not measured immediately after finishing the weight-reduction phase, but after some days of their usual diet.
It is possible that the introduction of a less stringent diet resulted in some water retention due to, for instance, increased sodium intake and retention. Unfortunately, the subjects' body weight change during the few days preceding the measurements was not recorded.

Two other groups ${ }^{4,10}$ also found an increased water fraction (against body weight and FFM) in obese subjects after weight reduction. Conceivably, the interval (weight maintenance) between weight reduction and body composition measurements should be longer than 1 week if the $3 \mathrm{M}$ model or underwater weighing are used.'

Bone mineral mass did not change during weight reduction. Some investigators have found $\mathrm{BMC}_{\mathrm{T}}$ losses (145 to $260 \mathrm{~g}$ ) during weight reduction, $, 411,12,30$ whereas others reported stable $\mathrm{BMC}_{\mathrm{T}}{ }^{6,31,32}$ Some of the measured changes in $\mathrm{BMC}_{\mathrm{T}}$ might be artifacts attributable to the change in fat thickness. ${ }^{4}$ In fact, using an older software version of XR-26 (version 2.2.2.) to analyze the present data, we also found a $100 \mathrm{~g}$ lower mean $\mathrm{BMC}_{\mathrm{T}}$ after weight reduction (results not shown). It is recommended that body composition researchers always use the latest DXA software. Because of unchanged $\mathrm{BMC}_{\mathrm{T}}$, the mineral fraction increased slightly during weight reduction. However, the simultaneous increase in the water fraction more than counterbalanced the effects of the increased mineral fraction on FFM density.

In the study by Albu et al, ${ }^{4}$ multicomponent models with TBW (4C and $3 \mathrm{~W}$ ) yielded comparable (within $0.5 \mathrm{~kg}$ ) mean estimates of composition of a $14-\mathrm{kg}$ weight loss in 10 women as compared with underwater weighing and DPA. Their results did not indicate any systematic variations in body hydration attributable to a long weight-maintenance period ( $\pm 1 \mathrm{~kg}$ for $\geq 4$ weeks). However, they noted that the individual changes in TBW were highly variable (from -10.9 to $+2.5 \mathrm{~L}$ ). To our knowledge, the present study is the first to report the distribution of error (SEE or SD) between FM change estimated by two-, three-, or four-component models. Therefore, a comparison against other studies was not possible.

Even before weight reduction, the $95 \%$ limits of agreement were much smaller for model $4 \mathrm{C}$ versus $3 \mathrm{~W}$ in comparison to $4 \mathrm{C}$ versus $3 \mathrm{M}$ or $\mathrm{UUW}$. The above comparison indicates an increased error when TBW is excluded from the mathematical 
equation. The individual errors of models $4 \mathrm{C}$ versus $3 \mathrm{M}$ and underwater weighing were larger yet after weight reduction, and were not reduced by including $B \mathrm{BMC}_{\mathrm{T}}$ in the equation (3M). These findings support the view that variation in TBW is more important than $\mathrm{BMC}_{\mathrm{T}}$ for the two-component model assumptions, even for absolute FM assessment in obese people. ${ }^{3,4}$

The use of a $3 \mathrm{~W}$ model has produced higher absolute FM estimates in obese subjects as compared with underwater weighing. ${ }^{26,27}$ These findings are in contrast to the present study. The equilibration time ( 10 hours in the present study) is a potential source of variation. In heavy people, such as the obese, a typical equilibration time ( 3 to 6 hours) might be too short for complete mixing of deuterium within the water compartment. ${ }^{33}$ An incomplete equilibration would lead to underestimated TBW, overestimated density of the FFM, and overestimated FM.

\section{$D X A$}

The present DXA results indicated an unbiased estimation for body fat loss. However, the distribution of error (SD of bias) was similar to that noted for other methods, excluding the $3 \mathrm{~W}$ model. Both the accurate mean estimation of composition of the weight loss and the large interindividual spread of results agree with the findings of Albu et al. ${ }^{4}$ While even half of the variance between two body composition methods may be associated with the criterion method, ${ }^{2}$ it still remains to be established why DXA does not seem more accurate in estimating fat loss than a simple equation with BMI.

In a recent study, Hendel et al $^{6}$ compared estimates of body composition change by DXA (Norland XR-36, software 2.4) and total body potassium (TBK) measurements. Obese subjects lost $10.6 \pm 6.8 \mathrm{~kg}$ body weight. The SD for the intermethod difference (DXA $v$ TBK) for FM loss was approximately $3 \mathrm{~kg}$, ie, larger than in the present study. However, the contrast between the present study and that of Hendel et $\mathrm{al}^{6}$ is difficult to interpret, because they used TBK and their subjects were both males and females.

FM was significantly overestimated and FFM underestimated by DXA (XR-26) both before and after weight reduction. This bias was reflected as very high estimates for the water fraction of FFM by DXA $\left(\mathrm{FFM}_{\mathrm{DXA}}=\mathrm{TBW} /\left[\mathrm{WT}-\mathrm{FM}_{\mathrm{DXA}}\right]\right)$ both before and after weight reduction: $78.9 \% \pm 3.4 \%$ and $81.1 \% \pm$ $3.8 \%$ before and after, respectively. The overestimation of FM was greater with increasing fatness, suggesting that the mathematical model for $x$-ray attenuation in fat is probably not entirely correct.

This overestimation of absolute FM corroborates our recent results with lean and normal-weight young women. ${ }^{13}$ However, the significant positive bias seems to be a concern for only $\mathrm{XR}-26,{ }^{34,35}$ and perhaps is also associated with the software version. When our entire data were analyzed with an older software version (2.2.2.), the biases were $10.3 \pm 2.9$ and $8.0 \pm$ $2.2 \mathrm{~kg}$ before and after weight reduction, respectively. Hence, the new software version has much less bias in obese subjects. The relative biases between other DXA instruments and criterion methods are usually small and more random. ${ }^{34-37}$

The SD for differences (error) between DXA and the $4 \mathrm{C}$ model was approximately $2 \mathrm{~kg}$ in the present study. Tataranni and Ravussin ${ }^{37}$ reported a larger error (SEE, $3.6 \mathrm{~kg}$ ) when DXA
(Lunar) was regressed against underwater weighing. The error was larger yet (SD $>4 \mathrm{~kg}$ ) when DXA (Norland XR-36) was compared against TBK. ${ }^{6}$ However, as noted earlier, these kinds of interstudy contrasts are not explicit, because of the use of different criterion methods.

\section{BIA and Skinfolds}

Both BIA and skinfolds underestimated fat loss, confirming previous results. ${ }^{9,38,39}$ Gray et al ${ }^{38}$ have suggested that changes in intraabdominal FM in obese people are proportionally larger than changes in subcutaneous fat, which is measured by skinfold calipers. Moreover, it was conjectured that body resistance, which is mostly dependent on TBW and water distribution between intracellular and extracellular water spaces, ${ }^{40}$ would also be insensitive to changes in intraabdominal fatness. ${ }^{39}$ These hypotheses are consistent with the observed underestimation of fat loss.

It was unexpected that body resistance increased but TBW remained unchanged during weight reduction. However, singlefrequency BIA, using the $50-\mathrm{kHz}$ frequency, is more dependent on extracellular water than on TBW volume. ${ }^{40}$ If the refeeding period resulted in increased intracellular water caused by increased glycogen resynthesis, this change in TBW is not necessarily reflected by BIA. Moreover, body resistance might be affected by small changes in the geometry of distal parts of the legs and arms $\mathrm{s}^{40}$ without a concomitant change in TBW.

The negative association between the bias of BIA and skinfolds observed both before and after weight reduction is similar to the results from Gray et al. ${ }^{38,39}$ In the present study, FM by the $4 \mathrm{C}$ model correlated positively with two measures of abdominal obesity, namely waist circumference (before weight reduction: $r=.63, P=.001$; after: $r=.76, P<.0001)$ and sagittal diameter of the abdomen (before: $r=.55, P=.001$; after: $r=.75, P<.0001$ ). Although correlations do not elucidate causal relations, our findings support the suggestion of Gray et $\mathrm{al}^{38.39}$ that variation in intraabdominal fatness is not accurately reflected by BIA or skinfolds.

Two studies have found skinfold measurements, with the Durnin and Womersley ${ }^{21}$ equation, to underestimate fat loss by 0.8 to $2.2 \mathrm{~kg}$ during weight reduction ${ }^{7,8}$ as compared with underwater weighing. The results concerning BIA are more variable (bias, -2.8 to $+1.6 \mathrm{~kg} \mathrm{FM}$ ), although most results indicate an underestimation of fat loss. ${ }^{7,8,24}$ Deurenberg et $\mathrm{al}^{5}$ reported that the error $(\mathrm{SD})$ between underwater weighing and BIA for estimation of FM loss was $2.2 \mathrm{~kg}$, ie, slightly larger than in our study. However, different criterion methods might affect the comparison between the present results and theirs.

The bias for absolute FM measurement was small between skinfolds and the $4 \mathrm{C}$ model. In fact, skinfolds, with the equation of Durnin and Womersley, ${ }^{21}$ seemed to provide an unbiased mean estimate of body fatness regardless of hydration status. However, individual errors were even larger than for BIA, precluding the use of skinfolds in very small groups or individuals. A larger relative error for skinfolds versus BIA (both compared against DXA) in obese subjects was also reported by Webber et al. ${ }^{9}$ Technical difficulties in measuring skinfolds in very obese subjects ${ }^{38}$ could explain the poor individual agreement.

As already noted by the original investigators, ${ }^{22}$ the BMI 
equation overestimated FM in obese subjects. However, the mean bias was almost unaffected by weight loss, resulting in a practically unbiased estimation of the composition of weight loss with this simple equation including only weight, height (squared), and age as independent variables. The individual errors versus the $4 \mathrm{C}$ model were large, but were not evidently different from those observed for other alternative methods, excluding only the $3 \mathrm{~W}$ model. Our findings suggest that a simple BMI-based equation might be as good as skinfolds or BIA in approximations of FM loss during weight reduction. However, the accuracy of the BMI equation is probably worse, if the composition of the weight loss is substantially different from a typical $15 \%$ to $25 \%$ FFM and $75 \%$ to $85 \%$ FM.

\section{Conclusions}

The present study is one of the first comparing a $4 \mathrm{C}$ model against $3 \mathrm{C}$ models, underwater weighing, and DXA for assessment of body composition changes in obese subjects. The results suggest that the two-component assumptions ${ }^{2,18}$ were valid in premenopausal, weight-stable obese women. However, particularly the water fraction was increased after weight reduction, making both underwater weighing and the $3 \mathrm{M}$ model unpredictable for assessment of large body composition changes. In fact, most methods underestimated fat loss, apparently because of unexpected changes in hydration of the fat-free body component. Therefore, use of multicomponent models with TBW is recommended when assessing changes in body composition during substantial weight reduction. DXA (Norland XR-26, software 2.5.2.) overestimated FM before and after weight reduction, but yielded an unbiased estimation of FM reduction.

\section{ACKNOWLEDGMENT}

We wish to acknowiedge the skillful assistance of Ulla Hakala, Hannele Hiilloskorpi, Kirsti Malmivuo, Kirsi Martinsen, Virpi Nieminen, and Tuija Pokki at the UKK Institute and Loek Wouters at the University of Limburg.

\section{REFERENCES}

1. Wang Z-M, Heshka S, Pierson RN, et al: Systematic organization of body-composition methodology: An overview with emphasis on component-based methods. Am J Clin Nutr 61:457-465, 1995

2. Lohman TG: Advances in Body Composition Assessment. Champaign, IL, Human Kinetics, 1992

3. Lohman TG, Going SB: Multicomponent models in body composition research: Opportunities and pitfalls, in Ellis KJ, Eastman JD (eds): Human Body Composition. New York, NY, Plenum, 1993, pp 53-58

4. Albu J, Smolowitz J, Lichtman S, et al: Composition of weight loss in severely obese women: A new look at old methods. Metabolism 41:1068-1074, 1992

5. Deurenberg P, Weststrate JA, Hautvast JGAJ: Changes in fat-free mass during weight loss measured by bioelectrical impedance and by densitometry. Am J Clin Nutr 49:33-36, 1989

6. Hendel HW, Gotfredsen A, Andersen T, et al: Body composition during weight loss in obese patients estimated by dual energy x-ray absorptiometry and by total body potassium. Int J Obes 20:1111-1116, 1996

7. van der Kooy K, Leenen $\mathrm{R}$, Deurenberg $\mathrm{P}$, et al: Changes in fat-free mass in obese subjects after weight loss: A comparison of body composition measures. Int J Obes 16:675-683, 1992

8. Ross R, Leger L, Martin P, et al: Sensitivity of bioelectrical impedance to detect changes in human body composition. J Appl Physiol 67:1643-1648, 1989

9. Webber J, Donaldson M, Allison SP, et al: A comparison of skinfold thickness, body mass index, bioelectrical impedance analysis and dual-energy $x$-ray absorptiometry in assessing body composition in obese subjects before and after weight loss. Clin Nutr 13:177-182, 1994

10. Vaswani AN, Vartsky D, Ellis KJ, et al: Effects of caloric restriction on body composition and total body nitrogen as measured by neutron activation. Metabolism 32:185-188, 1983

11. Compston JE, Laskey MA, Croucher PI, et al: Effect of diet-induced weight loss on total body bone mass. Clin Sci 82:429-432, 1992

12. Jensen LB, Quaade F, Sorensen OH: Bone loss accompanying voluntary weight loss in obese humans. J Bone Miner Res 9:459-463, 1994

13. Fogelholm GM, Kukkonen-Harjula TK, Sievänen HT, et al:
Body composition assessment in lean and normal-weight young women. Br J Nutr 75:793-802, 1996

14. Sievänen H, Oja P, Vuori I: Scanner-induced variability and quality assurance in longitudinal dual-energy $\mathrm{x}$-ray absorptiometry measurements. Med Phys 21:1795-1805, 1994

15. Schoeller DA, van Santen E, Peterson DW, et al: Total body water measurements in humans with ${ }^{18} \mathrm{O}$ and ${ }^{2} \mathrm{H}$ labelled water. Am J Clin Nutr 33:2686-2693, 1980

16. Lukaski HC, Johnston PE, Bolonchuk WW, et al: Assessment of fat-free mass using bioelectrical impedance measurements of the human body. Am J Clin Nutr 41:810-817, 1985

17. Harrison GG, Buskirk ER, Carter JEL, et al: Skinfold thicknesses and measurement technique, in Lohman TG, Roche AF, Martorell R (eds): Anthropometric Standardization Reference Manual, Abridged Edition. Champaign, IL, Human Kinetics, 1991, pp 55-70

18. Siri WE: The gross composition of the body, in Tobias CA, Lawrence JH (eds): Advances in Biological and Medical Physics. New York, NY, Academic, 1956, pp 239-280

19. Lohman TG: Applicability of body composition techniques and constants for children and youth. Exerc Sport Sci Rev 14:325-357, 1986

20. Segal KR, Van Loan M, Fitzgerald PI, et al: Lean body mass estimation by bioelectrical impedance analysis: A four-site crossvalidation study. Am J Clin Nutr 47:7-14, 1988

21. Durnin JVGA, Womersley J: Body fat assessed from total body density and its estimation from skinfold thickness: Measurements on 481 men and women aged from 16 to 72 years. Br J Nutr 32:77-97, 1974

22. Deurenberg P, Weststrate JA, Seidell JC: Body mass index as a measure of body fatness: Age- and sex-specific equations. Br J Nutr 65:105-114, 1991

23. Altman DG, Bland JM: Measurement in medicine: The analysis of method comparison studies. Statistician 32:307-317, 1983

24. Deurenberg P, Leenen R, van der Kooy K, et al: In obese subjects the body fat percentage calculated with Siri's formula is an overestimation. Eur J Clin Nutr 43:569-575, 1989

25. Fuller NJ, Elia M: Calculation of body fat in the obese by Siri's formula. Eur J Clin Nutr 44:165-166, 1990

26. Goran MI, Poehlman ET, Danforth E, et al: Comparison of body fat estimates derived from underwater weight and total body water. Int $J$ Obes 18:622-626, 1994

27. Fuller NJ, Sawyer MB, Elia M: Comparative evaluation of body 
composition methods and predictions, and calculation of density and hydration fraction of fat-free mass, in obese women. Int J Obes 18:503-512, 1994

28. Paijmans IJM, Wilmore KM, Wilmore JH: Use of skinfolds and bioelectrical impedance for body composition assessment after weight reduction. J Am Coll Nutr 11:145-151, 1992

29. Fuller NJ, Jebb SA, Laskey MA, et al: Four-component model for the assessment of body composition in humans: Comparison with alternative methods, and evaluation of the density and hydration of fat-free mass. Clin Sci 82:687-693, 1992

30. Pritchard JE, Nowson CA, Wark JD: Bone loss accompanying diet-induced or exercise induced weight loss: A randomized controlled study. Int J Obes 20:513-520, 1996

31. Nishizawa $Y$, Koyama $H$, Shoji $T$, et al: Altered calcium homeostasis accompanying changes of regional bone mineral during a very-low-calorie diet. Am J Clin Nutr 56:265S-267S, 1992

32. Ramsdale SJ, Bassey EJ: Changes in bone mineral density associated with dietary-induced loss of body mass in young women. Clin Sci 87:343-348, 1994

33. van Marken Lichtenbelt WD, Westerterp KR, Wouters L:
Deuterium dilution as a method for determining total body water: Effect of test protocol and sampling time. Br J Nutr 72:491-497, 1994

34. Clark RR, Kuta JM, Sullivan JC: Prediction of percent body fat in adult males using dual energy x-ray absorptiometry, skinfolds, and hydrostatic weighing. Med Sci Sports Exerc 25:528-535, 1993

35. Pierson RN, Wang $\mathbf{J}$, Thornton JC, et al: Bone mineral and body fat measurements by two absorptiometry systems: Comparisons with neutron activation analysis. Calcif Tissue Int 56:93-98, 1995

36. Snead DB, Birge SJ, Kohrt W: Age-related differences in body composition by hydrodensitometry and dual-energy $\mathrm{x}$-ray absorptiometry. J Appl Physiol 74:770-775, 1993

37. Tataranni PA, Ravussin E: Use of dual-energy $x$-ray absorptiometry in obese individuals. Am J Clin Nutr 62:730-734, 1995

38. Gray DS, Bray GA, Bauers M, et al: Skinfold thickness measurements in obese subjects. Am J Clin Nutr 51:571-577, 1990

39. Gray DS, Bray GA, Gemayel N, et al: Effect of obesity on bioelectrical impedance. Am J Clin Nutr 50:255-260, 1989

40. Foster KR, Lukaski HC: Whole-body impedance--What does it measure? Am J Clin Nutr 64:388S-396S, 1996 